\title{
Effect of Heart Rate on Major Adverse Cardiovascular Events in Hypertensive Patients with Different Ages and Genders
}

\author{
Yang $\mathrm{Xi}^{1}$; Ningling Sun ${ }^{1, *}$
}

\section{Summary \\ What is already known on this topic?}

The increase of heart rate will increase blood pressure, and the cardiovascular risk will increase when heart rate $>80$ beats/min $(\mathrm{bpm})$ in patients with hypertension.

What is added by this report?

Compared with patients who were female, $<65$ years old, and with hypertension, patients who were male, $\geq$ 65 years old, and with hypertension had the lowest risk of major adverse cardiovascular events (MACE) at baseline heart rate (HR) of 70-74 bpm.

What are the implications for public health practice?

Patients with hypertension should control their blood pressure well, and the HR of male and elderly patients should be managed well at the same time.

The previous follow-up study of the Kailuan cohort in Tangshan City, Hebei Province found that resting heart rate (HR) was associated with all-cause death; the risk of all-cause death was the lowest when heart rate was $68-72$ beats/min (bpm) and was the highest when heart rate exceeded $82 \mathrm{bpm}$ (1). Compared with the normal population, the related risk was higher in hypertensive population when heart rate was $>80 \mathrm{bpm}$ (2). The gender and age of patients with hypertension affected the prognosis of cardiovascular events (3), but whether it was related to heart rate was not clear. This study conducted cohort follow-up of patients with hypertension and analyzed the impact of baseline heart rate level on major adverse cardiovascular events (MACE) in patients with different ages and genders.

The HR, blood pressure (BP), systolic blood pressure (SBP), and diastolic blood pressure (DBP) of the patients were measured by Omron medical automatic electronic sphygmomanometers (model: hem-8102a). According to the baseline HR, patients were divided into 4 groups: $<70 \mathrm{bpm}, 70-74 \mathrm{bpm}$,
75-79 bpm, and $\geq 80 \mathrm{bpm}$. All patients with hypertension were treated with calcium antagonist (amlodipine). If the target BP was not met, other antihypertensive drugs would be added until the target BP was $<140 / 90 \mathrm{mmHg}$. After 24 months of followup, the effects of baseline HR on MACE were analyzed in hypertensive patients of different ages $(<65$ years old $/ \geq 65$ years old) and genders (male/female). The definition of MACE includes death, non-fatal stroke, non-fatal myocardial infarction, unstable angina pectoris, coronary intervention, coronary artery bypass grafting, newly onset atrial fibrillation, heart failure, and aortic dissection aneurysm, one of which criteria is enough for patient to be defined as MACE. All statistical analysis was performed by SAS (version 9.4, SAS Institute Inc., Cary, USA).

A total of 9,991 patients with hypertension from 110 hospitals in 21 cities* were enrolled in this study, including 5,045 males, 4,946 females, 5,400 patients aged $<65$ years, and 4,591 patients aged $\geq 65$ years. The mean age was $64.46 \pm 10.65$ years. The results showed that faster HR, younger age, and higher baseline SBP and DBP were all significant (all $P<0.001$ ) (Supplementary Table S1, available in http://weekly. chinacdc.cn/). After 24 months of antihypertensive drug treatment, SBP, DBP of hypertensive patients with different ages and genders were significantly lower than those at baseline $(P<0.001)$. HR of female patients after treatment was significantly lower than that of baseline $(P<0.001)$, but there was no significant difference in $\mathrm{HR}$ of male patients before and after treatment (Table 1).

The results showed that after adjusting for baseline BP, smoking, drinking, hyperlipidemia, diabetes, coronary heart disease, cerebrovascular disease, and taking beta blockers, the relative risk of MACE at baseline HR of 70-74 bpm in male and $\geq 65$ years old patients decreased by $41 \%$ and $40 \%$ [HR $=0.593$ (95\%CI: 0.401-0.876), $P=0.009$; HR=0.603 (95\%CI: 0.422-0.861), $P=0.005]$ (Table 2).

\footnotetext{
* 21 cities: Beijing, Hangzhou, Shanghai, Xuzhou, Nanjing, Guangzhou, Shenzhen, Changsha, Yinchuan, Jilin, Xi'an, Wuhan, Shenyang, Dalian, Tianjin, Zhengzhou, Chongqing, Chengdu, Jinan, Shijiazhuang, Handan.
} 
TABLE 1. Blood pressure and heart rate at baseline and 24 months follow-up in hypertensive patients with different ages and genders.

\begin{tabular}{|c|c|c|c|c|c|c|}
\hline \multirow{2}{*}{ Item } & \multicolumn{2}{|c|}{$\begin{array}{c}\text { Systolic blood pressure } \\
(\mathrm{mmHg})\end{array}$} & \multicolumn{2}{|c|}{$\begin{array}{c}\text { Diastolic blood pressure } \\
(\mathrm{mmHg})\end{array}$} & \multicolumn{2}{|c|}{ Heart rate (bpm) } \\
\hline & Baseline & 24 months follow-up & Baseline & 24 months follow-up & Baseline & 24 months follow-up \\
\hline $\begin{array}{c}\geq 65 \text { years old } \\
(n=4,591)\end{array}$ & $145.03 \pm 17.27$ & $130.97 \pm 7.28$ & $82.41 \pm 10.31$ & $77.00 \pm 6.19$ & $72.90 \pm 8.67$ & $71.52 \pm 5.81$ \\
\hline $\begin{array}{c}<65 \text { years old } \\
(n=5,400)\end{array}$ & $145.78 \pm 17.52^{*}$ & $130.27 \pm 6.99^{\dagger}$ & $87.21 \pm 10.52^{\dagger}$ & $78.21 \pm 5.75^{\dagger}$ & $74.08 \pm 7.93^{\dagger}$ & $71.81 \pm 5.42^{\dagger}$ \\
\hline Male $(n=5,045)$ & $145.40 \pm 17.09$ & $130.67 \pm 7.09$ & $85.52 \pm 10.74$ & $77.86 \pm 6.04$ & $71.73 \pm 8.28$ & $71.72 \pm 5.57$ \\
\hline Female $(n=4,946)$ & $145.47 \pm 17.73$ & $130.51 \pm 7.18$ & $84.27 \pm 10.57^{\S}$ & $77.45 \pm 5.94^{\S}$ & $73.33 \pm 8.32^{\S}$ & $71.63 \pm 8.32$ \\
\hline
\end{tabular}

Abbreviation: bpm=beats/min.

Note: Compared before and after 24 months treatment, except heart rate of male patients, $P$ values were $<0.001$; compared with $\geq 65$ years old, ${ }^{\star} P<0.05,{ }^{\dagger} P<0.01$; compared with male patients, ${ }^{\S} P<0.01$.

TABLE 2. Effects of different baseline heart rate levels on MACE in hypertensive patients with different ages and genders.

\begin{tabular}{|c|c|c|c|c|c|}
\hline Item & Baseline heart rate (bpm) & Hazard ratio $(95 \% \mathrm{Cl})$ & $P$ & Hazard ratio $(95 \% \mathrm{Cl})^{*}$ & $P$ \\
\hline \multicolumn{6}{|l|}{ Male } \\
\hline & $<70$ & $0.996(0.685-1.447)$ & 0.981 & $0.871(0.593-1.279)$ & $0.480^{\dagger}$ \\
\hline & $70-74$ & $0.639(0.436-0.935)$ & 0.021 & $0.593(0.401-0.876)$ & $0.009^{\dagger}$ \\
\hline & $75-79$ & $0.756(0.506-1.130)$ & 0.173 & $0.751(0.500-1.127)$ & $0.167^{\dagger}$ \\
\hline & $\geq 80$ & Ref & & Ref & \\
\hline \multicolumn{6}{|c|}{ Female } \\
\hline & $<70$ & $1.063(0.719-1.570)$ & 0.760 & $1.007(0.676-1.501)$ & $0.973^{\dagger}$ \\
\hline & $70-74$ & $0.860(0.584-1.266)$ & 0.445 & $0.891(0.601-1.321)$ & $0.567^{\dagger}$ \\
\hline & $75-79$ & $0.713(0.461-1.104)$ & 0.130 & $0.791(0.509-1.230)$ & $0.298^{\dagger}$ \\
\hline & $\geq 80$ & Ref & & Ref & \\
\hline \multicolumn{6}{|c|}{$<65$ years old } \\
\hline & $<70$ & $1.094(0.696-1.720)$ & 0.697 & $1.028(0.644-1.641)$ & $0.909^{\S}$ \\
\hline & $70-74$ & $0.941(0.611-1.450)$ & 0.784 & $0.963(0.620-1.496)$ & $0.866^{\S}$ \\
\hline & $75-79$ & $0.741(0.458-1.199)$ & 0.222 & $0.769(0.473-1.249)$ & $0.288^{\S}$ \\
\hline & $\geq 80$ & Ref & & Ref & \\
\hline \multicolumn{6}{|c|}{$\geq 65$ years old } \\
\hline & $<70$ & $0.892(0.637-1.248)$ & 0.505 & $0.853(0.604-1.205)$ & $0.369^{\S}$ \\
\hline & $70-74$ & $0.612(0.432-0.867)$ & 0.006 & $0.603(0.422-0.861)$ & $0.005^{\S}$ \\
\hline & $75-79$ & $0.751(0.516-1.092)$ & 0.134 & $0.784(0.537-1.146)$ & $0.209^{\S}$ \\
\hline & $\geq 80$ & Ref & & Ref & \\
\hline
\end{tabular}

Abbreviation: MACE=major adverse cardiovascular events.

${ }^{*}$ Adjusted for age/gender, baseline blood pressure, smoking, drinking, hyperlipidemia, diabetes, coronary heart disease, cerebrovascular disease, taking beta blockers.

${ }^{\dagger}$ Adjusted for age, baseline blood pressure, smoking, drinking, hyperlipidemia, diabetes, coronary heart disease, cerebrovascular disease, and taking beta blockers.

${ }^{\S}$ Adjusted for gender, baseline blood pressure, smoking, drinking, hyperlipidemia, diabetes, coronary heart disease, cerebrovascular disease, and taking beta blockers.

\section{DISCUSSION}

The increase of HR is a common clinical phenotype of hypertension. A cross-sectional survey of 115,229 patients with hypertension in 21 cities in China showed that $38.2 \%$ of the patients with hypertension had a HR of $\geq 80 \mathrm{bpm}$ (4). In European systolic hypertension trial, compared with patients with baseline HR $<80 \mathrm{bpm}$, patients with baseline HR $\geq 80$ bpm had an $89 \%$ increase in all-cause mortality risk after an average follow-up of 24 months (5). The previous studies in Chinese and Swedish suggested that there were age and gender differences in the prevalence, awareness, treatment, and control of 
hypertension (G). However, there are few studies on the optimal HR range of hypertensive patients of different ages and genders $(7)$.

The study compared baseline HR of patients with hypertension before treatment. The results showed that patients with faster baseline HR had higher baseline blood pressure and lower age. Previous studies have shown that increased HR is a biomarker of increased sympathetic activity (8). This study further suggested that the sympathetic activity was higher in younger patients with hypertension.

Previous studies have shown that estrogen affects the cardiovascular system, including inducing vasodilation, inhibiting vascular remodeling, regulating reninangiotensin-aldosterone system, and sympathetic nervous system. However, these protective effects can be significantly reversed in postmenopausal women (9). The mean age of hypertensive patients in this study was $64.46 \pm 10.65$ years old, and the female patients at this age were lacking estrogen. The disappearance of estrogen's protective effect in postmenopausal elderly women, which is closely related to increases in blood pressure variability, nocturnal blood pressure load, and cardiovascular events, is likely not related to MACE decreases in hypertensive patients with $\mathrm{HR}$ of 70-74 bpm. In addition, previous studies have suggested that elderly age is closely related to the occurrence of MACE, especially in patients with stage 2 hypertension, and the increased risk of MACE was only observed in $\geq 70$ years old patients $(10)$. The study showed that the relative risk of MACE was lower when $\mathrm{HR}$ was 70-74 bpm in hypertensive patients $\geq 65$ years. Strengthening the management of HR may reduce risk of MACE.

Furthermore, enrolled patients had been treated with standard antihypertensive drugs, which probably was one of the reasons that there was not much difference in systolic blood pressure between men and women and between younger and older people at baseline.

This study was subjected to some limitations. First, 24-hour Holter was not used to evaluate HR variability, which was the deficiency of heart rate analysis in this study. Second, this study was not a prospective study, further studies were needed to confirm the relationship between HR and MACE.

In summary, major adverse cardiovascular events increased when $H R$ was $\geq 80 \mathrm{bpm}$ in patients with hypertension. To better control the cardiovascular risk of male and elderly hypertensive patients over 65 years old, the HR should be controlled in the range of 70-74 bpm while the blood pressure is properly managed.

doi: $10.46234 / \mathrm{ccdcw} 2021.084$

\# Corresponding author: Ningling Sun, sunnl@263.net.

${ }^{1}$ Department of hypertension, Heart Center, Peking University People's Hospital, Beijing, China.

Submitted: February 24, 2021; Accepted: April 07, 2021

\section{REFERENCES}

1. Zhao MX, Zhao QH, Zheng MY, Liu T, Li Y, Wang M, et al. Effect of resting heart rate on the risk of all-cause death in Chinese patients with hypertension: analysis of the Kailuan follow-up study. BMJ Open 2020;10(3):e032699. http://dx.doi.org/10.1136/bmjopen-2019-0326 99.

2. Zhang X, Zhang M, Li C, Wang LH, Wu J, Huang ZJ, et al. Associations between hypertension status and increased heart rate China, 2015. China CDC Wkly 2020;2(40):771-5. http://dx. doi.org/10.46234/ccdcw2020.209.

3. Kang E, Lee S, Ha E, Oh HJ, Ryu DR. The effects of blood pressure components on cardiovascular events in a Korean hypertensive population according to age and sex: a nationwide population-based cohort study. Medicine (Baltimore) 2019;98(33):e16676. http://dx. doi.org/10.1097/MD.0000000000016676.

4. Sun NL, Huo Y, Huang J. The current status of heart rate in Chinese hypertensive patients. Chin J Hypertens 2015;23(10):934-9. http://dx.doi.org/10.16439/j.cnki.1673-7245.2015.10.013. (In Chinese).

5. Palatini P, Thijs L, Staessen JA, Fagard RH, Bulpitt CJ, Clement DL, et al. Predictive value of clinic and ambulatory heart rate for mortality in elderly subjects with systolic hypertension. Arch Intern Med 2002;162(20):2313 - 21. http://dx.doi.org/10.1001/archinte.162.20. 2313.

6. Santosa A, Zhang Y, Weinehall L, Zhao GM, Wang N, Zhao Q, et al. Gender differences and determinants of prevalence, awareness, treatment and control of hypertension among adults in China and Sweden. BMC Public Health 2020;20(1):1763. http://dx.doi.org/10. 1186/s12889-020-09862-4.

7. Gillis EE, Sullivan JC. Sex differences in hypertension: recent advances. Hypertension 2016;68(6):1322 - 7. http://dx.doi.org/10.1161/HYPER TENSIONAHA.116.06602.

8. Esler M, Lambert G, Esler D, Ika Sari C, Guo L, Jennings G. Evaluation of elevated heart rate as a sympathetic nervous system biomarker in essential hypertension. J Hypertens 2020;38(8):1488 95. http://dx.doi.org/10.1097/HJH.0000000000002407.

9. Di Giosia P, Giorgini P, Stamerra CA, Petrarca M, Ferri C, Sahebkar A. Gender differences in epidemiology, pathophysiology, and treatment of hypertension. Curr Atheroscler Rep 2018;20(3):13. http://dx.doi.org/ 10.1007/s11883-018-0716-z.

10. Kim H, Lee S, Ha E, Kwon SH, Jeon JS, Noh H, et al. Age and sex specific target of blood pressure for the prevention of cardiovascular event among the treatment naive hypertensive patients. Sci Rep 2020;10(1):21538. http://dx.doi.org/10.1038/s41598-020-78641-3. 
SUPPLEMENTARY TABLE S1. Baseline characteristics of hypertensive patients with different baseline heart rates [( $\bar{x} \pm \mathrm{s})$, $\mathrm{n}(\%)]$.

\begin{tabular}{|c|c|c|c|c|c|c|}
\hline Baseline HR (bpm) & Age (years) & BMI $\left(\mathrm{kg} / \mathrm{m}^{2}\right)$ & SBP $(\mathrm{mmHg})$ & DBP $(\mathrm{mmHg})$ & Diabetes (\%) & Hyperlipidemia (\%) \\
\hline Total $(n=9,991)$ & $64.46 \pm 10.65$ & $24.61 \pm 2.82$ & $145.43 \pm 17.41$ & $84.90 \pm 10.67$ & $1,477(14.78)$ & $858(8.59)$ \\
\hline$<70(n=2,655)$ & $65.74 \pm 10.73$ & $24.59 \pm 2.81$ & $143.23 \pm 17.07$ & $82.75 \pm 10.87$ & $422(15.89)$ & $250(9.42)$ \\
\hline $70-74(n=3,589)$ & $64.47 \pm 10.47^{*}$ & $24.53 \pm 2.78$ & $143.59 \pm 16.65$ & $84.13 \pm 10.16^{*}$ & $507(14.13)$ & $294(8.19)$ \\
\hline $75-79(n=2,305)$ & $63.28 \pm 10.37^{*}, \dagger$ & $24.72 \pm 2.78$ & $146.35 \pm 16.83^{*}, \dagger$ & $85.99 \pm 10.10^{*}+\dagger$ & $320(13.88)$ & $188(8.16)$ \\
\hline \multirow[t]{2}{*}{$\geq 80(n=1,442)$} & $63.94 \pm 11.17^{*}$ & $24.66 \pm 2.99$ & $152.62 \pm 18.73^{*}, t, \S$ & $89.04 \pm 11.10^{*}, t$, & $228(15.81)$ & $126(8.74)$ \\
\hline & $F=23.409$ & $F=2.355$ & $F=115.527$ & $F=126.957$ & $x^{2}=6.525$ & $x^{2}=3.627$ \\
\hline$P$ value & $<0.001$ & 0.070 & $<0.001$ & $<0.001$ & 0.089 & 0.305 \\
\hline
\end{tabular}

Abbreviation: SBP=systolic blood pressure; $\mathrm{DBP}=$ diastolic blood pressure; HR=heart rate; bpm=beats/min.

* compared with $<70 \mathrm{bpm}, P<0.05$.

${ }^{\dagger}$ compared with 70-74 bpm, $P<0.05$.

$\S$ compared with $75-79 \mathrm{bmp}, P<0.05$. 